\title{
On-Site Engineering Test of Active Support Control for the PV Station and Wind Farm in the AC-DC Hybrid Power Grid under Extreme Fault Conditions
}

\author{
Xiao-ling Su $\mathbb{D}^{1,2}$ Lai-jun Chen $\mathbb{D}^{2},{ }^{2}$ Jun Yang, ${ }^{3}$ Zhengxi Li, ${ }^{3}$ Peng Zhou, ${ }^{3}$ and Hui Chen ${ }^{3}$ \\ ${ }^{1}$ School of Water Resources and Electric Power, Qinghai University, Xining 810016, China \\ ${ }^{2}$ Qinghai Key Lab of Efficient Utilization of Clean Energy (Tus-Institute for Renewable Energy), Qinghai University, \\ Xining 810016, China \\ ${ }^{3}$ State Grid Qinghai Electric Power Company, Xining 810016, China
}

Correspondence should be addressed to Lai-jun Chen; chenlaijun@qhu.edu.cn

Received 4 June 2021; Revised 20 June 2021; Accepted 7 July 2021; Published 5 August 2021

Academic Editor: Chun Wei

Copyright (C) 2021 Xiao-ling Su et al. This is an open access article distributed under the Creative Commons Attribution License, which permits unrestricted use, distribution, and reproduction in any medium, provided the original work is properly cited.

\begin{abstract}
Power systems have developed significantly because of the increasing share of renewable energy sources (RESs). Despite the advantages, they also bring inevitable challenges to power system stability, especially under extreme fault conditions. This paper presents a practical active support control strategy for RESs to support the power grid under extreme fault conditions. The proof process is taken in an AC-DC hybrid power grid integrated with large capacity of PV stations and wind farms. The on-site engineering test results reflect that RESs bring potential risks in the AC-DC hybrid power grid operation and validate the excellent engineering practical features of the proposed control strategy. In addition, test results also reveal predisposing factors of power system instability which are missing in the simulation and fault simulation device-based testing results. They prove the outstanding advantages of on-site engineering tests.
\end{abstract}

\section{Introduction}

Power systems see more and more photovoltaic (PV) and wind generation integration. Within increasing renewable energy source (RES) penetration level, despite the advantages such as environmental friendly and sustainable development, it also brings problems to the utility grid [1-3]. Adjusting the power source structure brings an inevitable impact on the power system primary frequency response due to the conventional generators' reduction and consequent loss of inertia [4]. Therefore, the provision of ancillary services is becoming an increasingly challenging task to this new generation power system operation.

The power source structure has developed significantly because of the increasing share of RESs in the power system, and the coupling interaction between RESs and the power grid is becoming significant which reduces delivery capability and power accommodation capacity of the power system [5]. In addition, within disturbance rejection ability and robust stability, low overload capacity, insufficient tolerance to voltage changes, and all these characteristics of power electronic equipment may also deteriorate the power system operation environment even further.

Most of the PV stations and wind farms do not participate in power grid control at the present stage. Some large-scale grid-connected PV stations or wind farms adjust output power according to the automatic generation control (AGC) and automatic voltage and reactive power control (AVC) system to regulate voltage and frequency as power system requirements [6, 7]. Consequently, the conventional control or operation mode is no longer efficient in the new generation power system $[8,9]$. Zhang et al. [10] studied the control performance of AGC for wind power ramping based on deep reinforcement learning. Prasad and Padhy [11] proposed the synergistic frequency regulation control mechanism for DFIG wind turbines with optimal pitch dynamics. Complicated stochastic AGC modeling causes high computational burdens concurrently. Chen et al. [12] 
used the Itô-theory-based model to reduce the computational burden of optimization considering non-Gaussian wind power uncertainty. However, random communication delay and noise disturbance in the AGC/AVC control network usually cause the control system performance degradation or even system destabilization.

To address these challenges, the PV station and wind farm should provide active support to the power system in external faults and other transient processes. Using ESSs to add regulation capacity and improve the dynamic performance of AGC, particularly at the high RES penetration power systems, is a feasible solution [13-16]. Su et al. [17] proposed an adaptive robust sliding-mode control for energy storage system integrated $\mathrm{PV}$ and wind station to provide frequency and voltage control functionality for RESs. Wang et al. [18] used the supercapacitor in the largescale hybrid wind-PV farm to improve stability in the multimachine power system. The large-scale grid-connected PV station or wind farm requires a large-capacity energy storage system which is not available at present. Therefore, it is more practical to use existing equipment such as the PV inverter and wind power generator and also conventional reactive power compensators such as static VAR compensator (SVC) or static VAR generator (SVG) to provide active support to the power grid. Karbouj et al. [19] proposed a selfadaptive voltage controller to enable solar PV power plant participation in voltage control ancillary service. STATCOM is used in large PV stations for fault-induced delayed voltage recovery alleviation in [20]. A coordinated damping optimization control strategy for wind power generators and their reactive power compensators is proposed in [21]. Wang et al. [22] analyzed the interval overvoltage risk caused by the impacts of load uncertainties and SVC.

Simulation and laboratory tests based on theoretical deduction are the most frequently used method in RES control strategy validation or power system. The performance of the proposed controller in [9] is demonstrated using simulation studies of an interconnected power system which are conducted within the DIgSILENT Power Factory platform. Case studies in [17] were developed based on MATLAB, while Varma and Mohan [20] presented the validation process by PSCAD/EMTDC. A three-phase fourwire hybrid simulation platform integrating the advantages of both digital simulation and physical simulation is developed in [23] which combines the physical simulation system and real-time digital simulator. Wang et al. [24] built laboratory platforms for experimental verification. Zimmerman et al. [25] presented the details of the network modeling and problem formulations used by MATPOWER. Reshikeshan et al. [26] verified the proposed autonomous voltage regulation scheme by power flow simulations on the EPRI Circuit 24 test feeder in an open-source distribution system simulation platform.

The large-scale PV station or wind farm is connected to the power grid with long electrical distance, and the reactive power control capability is relatively insufficient which makes voltage stability a challenging task for the power system, especially during large disturbances [27-30]. Laboratory tests only validate the operation performance of $\mathrm{PV}$ inverters or wind generators in the islanding mode, and some proof processes are taken in the microgrid. The power system is a very complicated, nonlinear, and strong coupling dynamic system, and experimental results based on islanding or gridconnecting setup are inadequate when it comes to a largescale grid-connected PV station or wind farm.

On the contrary, the fault simulation device is the common option in RES on-site testing. However, because of the maximum voltage and current limitation, its capacity is also limited; consequently, it is almost impossible to simulate the power system. Fault simulation device is applied to PV inverter and wind generator onsite experiments; however, it is inadequate for large RESs station onsite engineering test, as it is impossible to simulate voltage waveform at grid connection point of RESs station by fault simulation device.

Therefore, the on-site engineering tests are necessary in the PV station and wind farm active support control study. The power system with large-scale RES and power electric device-based projects such as high-voltage direct current (HVDC) have much more possibility of voltage and frequency instability.

This paper proposes a practical active support control for the PV station and wind farm to support the power grid under extreme fault conditions. The excellent engineering practical features of the proposed control strategy are important since active support capability is an obligation for the PV station and wind farm in the future, and upgrading the RES with the large-capacity energy storage system is uneconomical, plus for some PV stations or wind farms, there is no space for ESSs. In addition, their control capability is verified through on-site engineering test in an ACDC hybrid power grid integrated with large capacity of the PV station and wind farm. The on-site test includes three categories, and each has fifteen grounding faults at different sites.

\section{Proposed Active Support Control for the PV Station and Wind Farm}

In this section, the construction of the proposed active support control strategy for the PV station and wind farm is presented. Figure 1 gives the topology of the PV station. The $\mathrm{PV}$ inverters are connected to the power grid through a $10 \mathrm{kV} / 35 \mathrm{kV}$ transformer; then, it is integrated to a $110 \mathrm{kV}$ collection substation through a $35 \mathrm{kV} / 110 \mathrm{kV}$ transformer with a long transmission line.

The topology of the wind farm is presented in Figure 2. The wind power generators are connected to the power grid through a $0.69 \mathrm{kV} / 35 \mathrm{kV}$ transformer; then, it is integrated to a $110 \mathrm{kV}$ collection substation through a $35 \mathrm{kV} / 110 \mathrm{kV}$ transformer with a long transmission line.

2.1. High-Frequency Resistance Control. Primary frequency regulation is insufficient in a weak AC/DC hybrid power system, which makes high frequency problem an ineluctable challenge for RESs operation. Under this condition, the PV inverter, wind power generator, SVC, SVG in the PV station, and wind farm should maintain grid-connected operation 


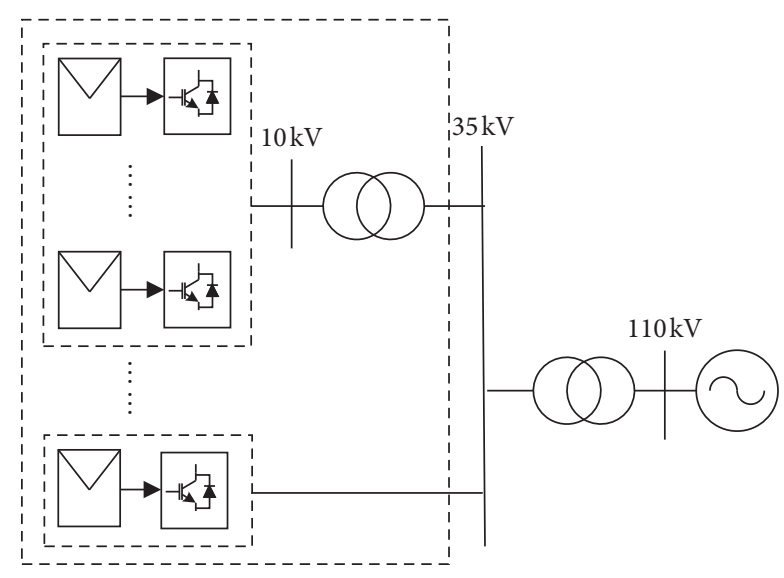

FIGURE 1: PV station topology.

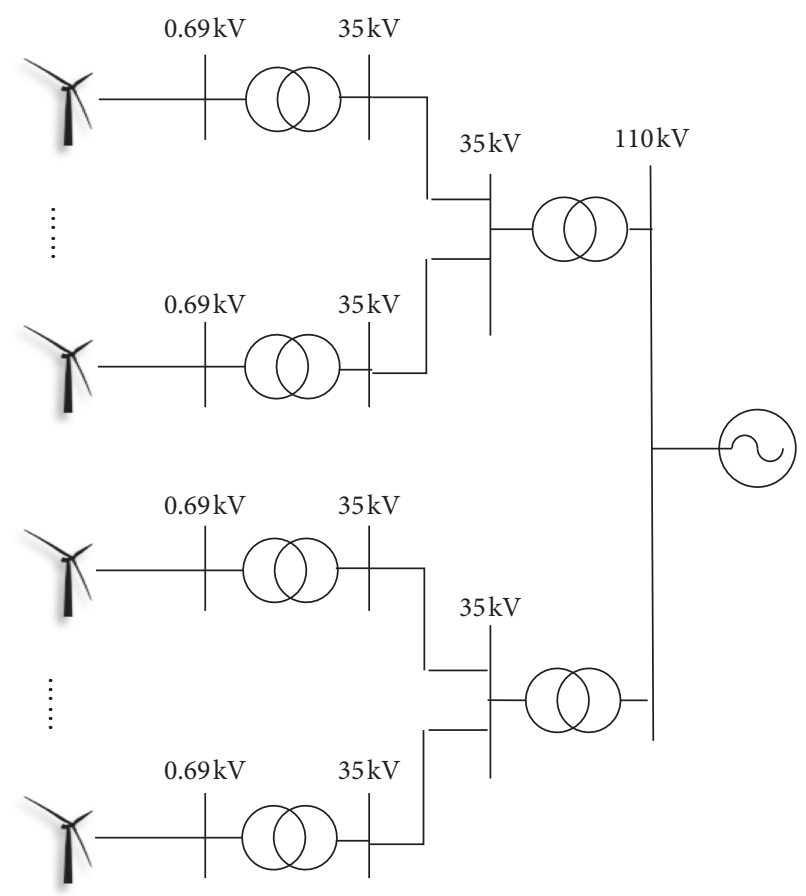

Figure 2: Wind farm topology.

and provide dynamic support to the power system simultaneously. The high-frequency resistance control strategy is designed as

$$
\begin{cases}49.5 \mathrm{~Hz} \leq f_{T}<50.5 \mathrm{~Hz}, & \text { continuous, } \\ 50.5 \mathrm{~Hz} \leq f_{T}<51.0 \mathrm{~Hz}, & t_{T} \geq 3 \mathrm{~min}, \\ 51.0 \mathrm{~Hz} \leq f_{T}<51.5 \mathrm{~Hz}, & t_{T} \geq 10 \mathrm{~s}, \\ 51.5 \mathrm{~Hz}<f_{T}, & t_{T} \geq 2 \mathrm{~s},\end{cases}
$$

where $f_{T}$ is the frequency at the access point and $t_{T}$ is the operation time requirement. Take a PV inverter for example; by adopting this control law, it remains in the gridconnected mode when the power system frequency is greater than or equal to $49.5 \mathrm{~Hz}$ and less than $50.5 \mathrm{~Hz}$. When the frequency is greater than or equal to $50.5 \mathrm{~Hz}$ and less than
51.0 Hz, the PV inverter will remain in the grid-connected mode for over $3 \mathrm{~min}$.

2.2. High-Voltage Resistance Control. Insufficient voltage control ability of the power system brings high-voltage challenge to RESs. In the steady state, the PV inverter, wind power generator, SVC, SVG in the PV station, and wind farm operate in the grid-connected mode, and they provide dynamic support to the power system during the transient state. High-voltage resistance control is designed as

$$
\begin{cases}0.9 \text { p.u. } \leq U_{T}<1.1 \text { p.u., } & \text { continuous, } \\ 1.1 \text { p.u. } \leq U_{T}<1.2 \text { p.u., } & t_{T} \geq 10 \mathrm{~s}, \\ 1.2 \text { p.u. } \leq U_{T}<1.3 \text { p.u., } & t_{T} \geq 0.5 \mathrm{~s},\end{cases}
$$

where $U_{T}$ is the voltage per unit value at the access point and $t_{T}$ is the operation time requirement. Take the PV inverter for example; by adopting this control law, it remains in the grid-connected mode no less than 10 seconds when its access point voltage is greater than 1.1 p.u. and less than 1.2 p.u..

2.3. Low-Voltage Ride-Through Control. Low-voltage ridethrough (LVRT) technology is one important indicator for the PV station and wind farm; the control logic is divided into 3 parts.

2.3.1. Current Coefficient for Reactive Power Control. The PV station and wind farm provide dynamic reactive power support for the grid during LVRT. The control strategy for dynamic reactive current increment $\Delta I_{q \mathrm{LVRT}}$ of the PV inverter and direct-drive permanent magnet generator is

$$
\begin{cases}\Delta I_{q \mathrm{LVRT}} \geq K_{1}\left(U_{\mathrm{LV}}-U_{T}\right) I_{N}, & \left(0.2 \text { p.u. } \leq U_{T} \leq 0.9 \text { p.u. }\right), \\ \Delta I_{q \mathrm{LVRT}} \geq 1.05 I_{N}, & \left(U_{T}<0.2 \text { p.u. }\right), \\ \Delta I_{q \mathrm{LVRT}}=0, & \left(U_{T} \geq 0.9 \text { p.u. }\right),\end{cases}
$$

where $U_{\mathrm{LV}}$ is the threshold of LVRT, $U_{T}$ is the voltage per unit value at the access point, $K_{1}$ is the current coefficient for reactive power control, and $I_{N}$ is the rated current of the equipment. $I_{q \mathrm{LVRT}}$ reduces to zero in $10 \mathrm{~ms}$ after power grid voltage recovery.

2.3.2. Current Coefficient for Active Power Control. The PV station and wind farm generate reactive power during LVRT in the first instance, and the active current $I_{p \mathrm{LVRT}}$ remains as the current before faults if its current is less than the current threshold; otherwise,

$$
I_{P \mathrm{LVRT}}=K_{2} I_{P 0},
$$

where $I_{p o}$ is the current before faults or before voltage drop and $K_{2}$ is the current coefficient for active power control during LVRT. $K_{2}$ is equal to 1 if output current is less than the current threshold and current coefficient $K_{1}$ meets the requirements in equation (3). 
2.3.3. Active Power Recovery Rate. The active power returns to its value before fault, and recovery speed is

$$
\Delta P_{\mathrm{LVRT}}=K_{P} P_{N},
$$

where $P_{N}$ is the rated power of the equipment and $K_{P}$ is the recovery coefficient for active power, and its recommended value is 3 .

2.4. High-Voltage Ride-Through Control. High-voltage ridethrough (HVRT) is another important indicator for the PV station and wind farm. The PV station and wind farm absorb dynamic reactive power from the grid during HVRT. The control strategy for dynamic reactive current increment $\Delta I_{q \text { HVRT }}$ of the PV inverter and direct-drive permanent magnet generator is

$$
\begin{cases}\Delta I_{q \mathrm{HVRT}} \leq K_{3}\left(U_{\mathrm{HV}}-U_{T}\right) I_{N}, & \left(U_{T} \geq 1.1 \text { p.u. }\right), \\ \Delta I_{q \mathrm{HVRT}}=0, & \left(U_{T}<1.1 \text { p.u. }\right),\end{cases}
$$

where $U_{\mathrm{HV}}$ is the threshold of HVRT, $U_{T}$ is the voltage per unit value at the access point, $K_{3}$ is the current coefficient for reactive power control and its recommended value is over 1.5 , and $I_{N}$ is the rated current of the equipment.

With sufficient primary energy, the output active power remains as its value before fault if its output current is less than the current threshold and current coefficient $K_{3}$ meets the requirements in equation (6).

2.5. Continuous Ride-Through Control. Continuous occurrence of commutation failure in the HVDC system causes alternating high voltage and low voltage; the control strategy is designed in Figure 3 to cope with these operating conditions. When high/low voltage occurs, the PV station and wind farm not only can remain in grid-connected operation but also meet the requirements above.

\section{AC-DC Hybrid Power Grid within Large- Scale RESs}

Voltage and frequency control is more challenging in the power system when the penetration level of the RES is relatively high. HVDC is another disturbance factor when it comes to power system stability. In order to validate the active support control under extreme conditions, on-site engineering tests are performed in an AC-DC hybrid power grid as shown in Figure 4. The main voltage class of this grid is $750 / 330 / 110 \mathrm{kV}$, and it has 194 substations $(110 \mathrm{kV}$ and above) and two HVDC transmission projects in this system. It covers an area of 622,000 square kilometers which is characterized as long-distance and large-capacity transmission.

3.1. Long Distance. PV and wind power generated in the west of this power system transmit to the load center through $800 \mathrm{~km} 750 \mathrm{kV}$ AC transmission lines. PV, wind power, and hydropower from the south part of this power

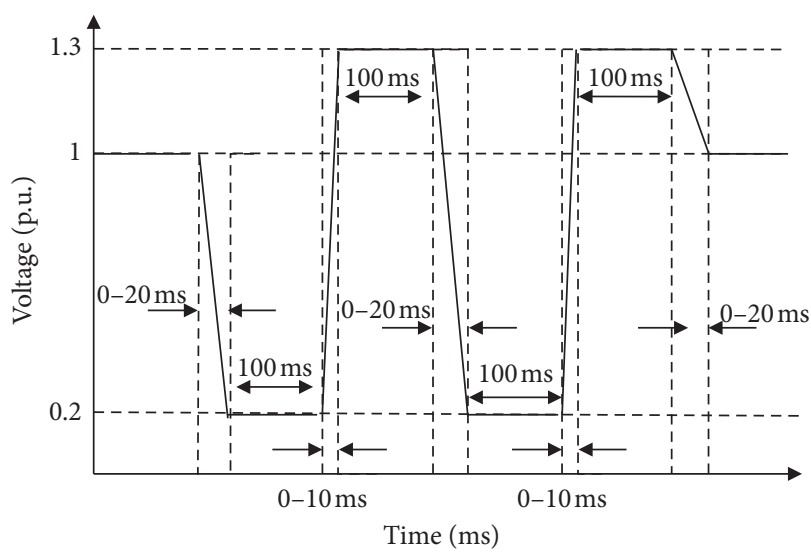

Figure 3: Continuous ride-through control strategy.

system transmit to the load center through $150 \mathrm{~km} 750 \mathrm{kV}$ AC transmission lines.

3.2. Large Capacity. By the end of 2020, the total installed capacity is 40.3 million $\mathrm{kW}$, hydropower, thermal power, wind power, photovoltaic, and solar thermal power accounting for $29.6 \%, 9.8 \%, 20.9 \%, 39.2 \%$, and $0.5 \%$, respectively, as shown in Figure 5 . The renewable sources accounted for $60.7 \%$, which is the largest installed power in this power grid.

3.3. Power Fluctuation and Stochastic Characteristic. Power fluctuation and stochastic characteristic of PV and wind generation bring uncontrollable problems to this power system. In addition, synchronous compensator, energy storage systems, and solar thermal power station make the operation mode of the power grid complex and changeable both in time domain range and geographical scope.

3.4. Small Load Scale. First, $86 \%$ of the power system load is connected to Station 2 and Station 6; meanwhile, only $0.5 \%$ of the power system load is connected to Station 3, Station 4, and Station 5. This type of load distribution is seriously uneven. Second, most of the load is large industrial load, accounted for $84 \%$, which brings harmonics and voltage surges. Third, the load variation ratio is relatively small, with the average load rate equal to $95.7 \%$, and a maximum peakvalley difference is $10 \%$. Fourth, the total load is small compared to its total installed capacity; the historical maximum load is 10 million $\mathrm{kW}$.

3.5. Insufficient Stable Power Source near the HVDC Converter Station. There is only one hydropower station near the $\pm 800 \mathrm{kV} \mathrm{HVDC}$ converter station and over the PV station and wind farm. So, the coupling effect between the HVDC transmission system and AC power system is significant. In addition, disturbance from the PV station and wind farm is also remarkable for this HVDC converter station. 


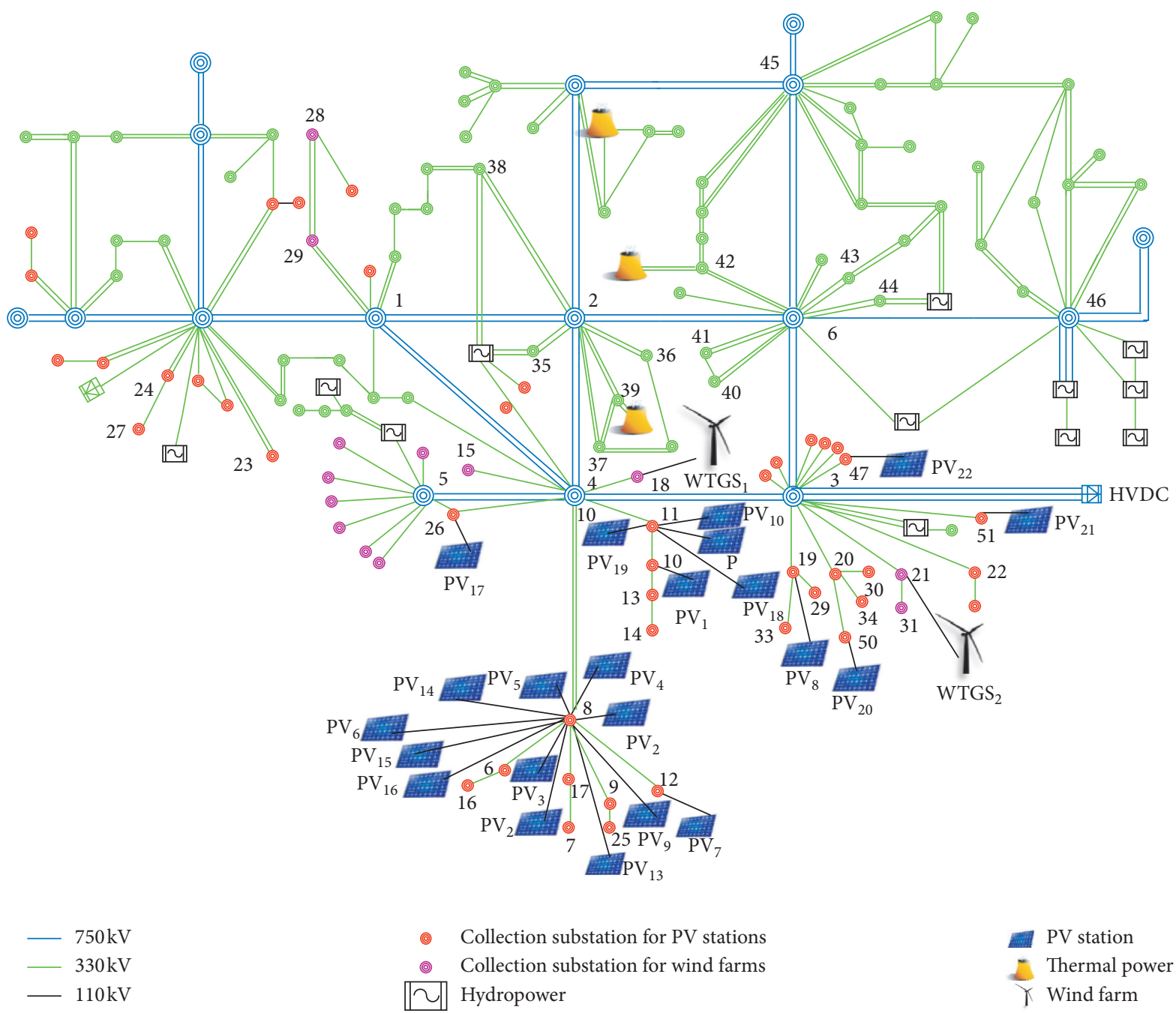

Figure 4: AC-DC hybrid power grid.

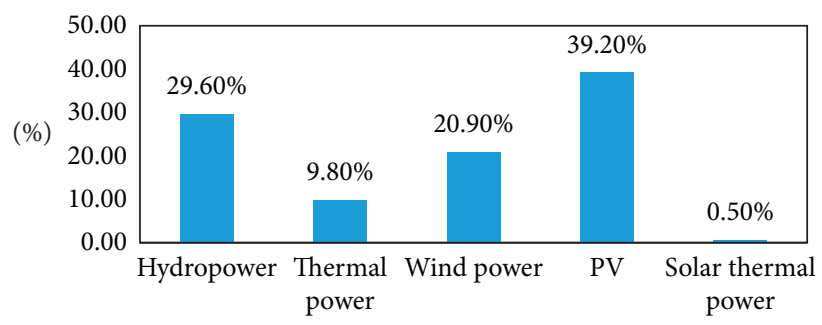

FIgURE 5: Installed capacity.

The AC power system near the $\pm 800 \mathrm{kV}$ HVDC converter station is a weak AC/DC hybrid power system. In this power system, insufficient voltage control and primary frequency regulation ability make RESs face problems such as overvoltage or low voltage constantly. It is the best on-site engineering test platform to verify the proposed active support control for the PV station and wind farm.

\section{On-Site Experiments}

The control strategy for the PV station and wind farm is test through on-site artificial fault tests which can be divided into three categories, and each category has fifteen grounding faults at different sites. There are over $200 \mathrm{PV}$ stations and 30 wind farms that participated in these experiments. 54 of the $\mathrm{PV}$ stations and 5 of the wind farms adopt the proposed active support control strategy. Recommended control parameters for the $\mathrm{PV}$ inverter and direct-drive wind generator are given in Table 1 .

To deal with the large-scale experimental data and waveform in the on-site engineering test, the monitoring location is chosen according to simulation analysis results and power grid operation experience. The chosen monitoring locations are (1) PV inverter, wind power 
TABLE 1: Recommended control parameters.

\begin{tabular}{lccccc}
\hline Parameter & Value & Parameter & Value & Parameter & Value \\
\hline$U_{\mathrm{LV}}$ & 0.9 & $K_{1}$ & $1.5-2$ & $K_{3}$ & $K_{P}$ \\
$U_{\mathrm{HV}}$ & 1.1 & $K_{2}$ & $=1$ & $\geq 1.5$ \\
\hline
\end{tabular}

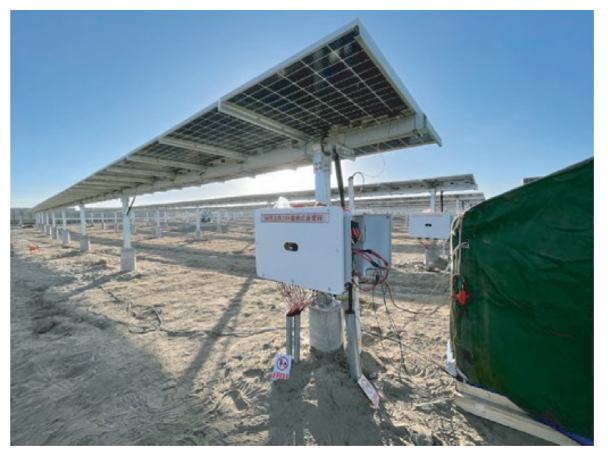

(a)

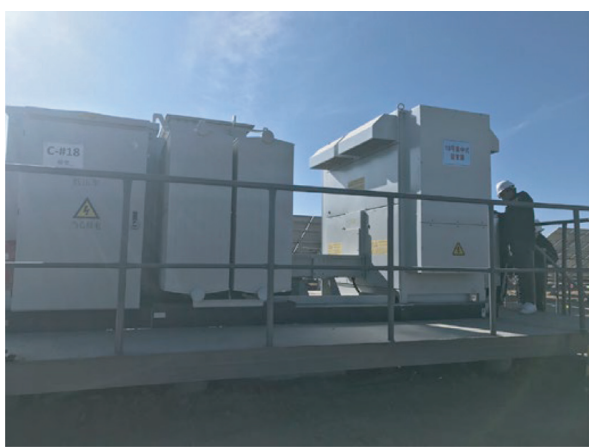

(b)

Figure 6: PV inverters in PV station 8. (a) Series-connected PV inverter. (b) Centralized PV inverter.

generator, SVC, and SVG in the PV station and wind farm; (2) PMU and fault recording device in all $750 \mathrm{kV}$ substations and some $330 \mathrm{kV}$ substations; (3) $\pm 800 \mathrm{kV} \mathrm{HVDC}$ converter station; (4) PMU and fault recording device in the $110 \mathrm{kV}$ collection substation near the $\pm 800 \mathrm{kV} \mathrm{HVDC}$ converter station; (5) $750 \mathrm{kV} / 330 \mathrm{kV} / 110 \mathrm{kV}$ transmission line and some $35 \mathrm{kV}$ transmission lines in the PV station and wind farm.

4.1. Inverter Parameters in PV Station 8. This paper presents testing results of PV station 8 . Its capacity is $100 \mathrm{MW}$ and connects to collection station 19. There are two types of PV inverters, series-connected PV inverter and centralized PV inverter, which are shown in Figure 6. The key parameters of the series-connected PV inverter are given in Table 2, and Table 3 gives key parameters of the centralized PV inverter.

The original and modified control parameters of seriesconnected PV inverters and centralized PV inverters in PV station 8 are given in Table 4 . In order to avoid SVC or SVG disconnection during experiments, the voltage protection setting value of the SVC and SVG is adjusted to $0.6 U_{N}$ and $1.2 U_{N}$, where $U_{N}$ is its rated voltage.

4.2. Experimental Results. There is a grounding fault on phase A of $330 \mathrm{kV}$ transmission line 3-19 near station 3. The voltage and current waveform of this transmission line from PMU is given in Figures 7 and 8. Figure 9 is the power and frequency waveform. The experiment result shows that the voltage on phase A of this line drops significantly because of the grounding fault, and instantaneous short circuit occurs when the fault occurs.

Figures 10 and 11 present output voltage and current waveforms of the centralized PV inverter in PV station 8. And its output active and reactive power is given in Figure 12.
Table 2: Parameters of the series-connected PV inverter.

\begin{tabular}{lc}
\hline DC max. input voltage & $1500 \mathrm{VDC}$ \\
DC max. input current & $9 \times 40 \mathrm{~A}$ \\
IsC & $9 \times 40 \mathrm{~A}$ \\
DC MPP range & $500-1500 \mathrm{VDC}$ \\
AC output nominal voltage & $800 \mathrm{VAC}$ \\
AC nominal operating frequency & $50 \mathrm{~Hz}$ \\
AC output rated power & $175 \mathrm{~kW}$ \\
AC output max. apparent power & $193 \mathrm{kVA}$ \\
AC output max. current & $140.7 \mathrm{~A}$ \\
Power factor & $-0.8-0.8$ \\
\hline
\end{tabular}

TABLE 3: Key parameters of the centralized PV inverter.

\begin{tabular}{lc}
\hline DC max. input voltage & $1500 \mathrm{VDC}$ \\
DC max. input current & $3062 \mathrm{~A}$ \\
IsC & $4200 \mathrm{~A}$ \\
DC MPP range & $1150-1500 \mathrm{VDC}$ \\
DC input channel & 17 \\
AC output nominal voltage & $800 \mathrm{VAC}$ \\
AC nominal operating frequency & $50 \mathrm{~Hz}$ \\
AC output rated power & $3150 \mathrm{~kW}$ \\
AC output max. apparent power & $3465 \mathrm{kVA}$ \\
AC output max. current & $2273 \mathrm{~A}$ \\
Power factor & $-0.8-+0.8$ \\
Transformer ratio & $37 / 0.8 \mathrm{kVAC}$ \\
\hline
\end{tabular}

Figures 13 and 14 present output voltage and current waveforms of the series-connected PV inverter in PV station 8. And its output active and reactive power is given in Figure 15.

Figures 16 and 17 present voltage and current waveforms at one point of common coupling (PCC) in PV station 8. The power flow value of this PCC is given in Figure 18.

Figures 19 and 20 present voltage and current waveforms at another point of common coupling (PCC) in PV station 8. The power flow value of this PCC is given in Figure 21.

Table 5 gives the voltage value at the high voltage side of main transformer \#1 in $750 \mathrm{kV}$ and $330 \mathrm{kV}$ substations; the 
TABLE 4: Control parameters of PV inverters in PV station 8.

\begin{tabular}{lcccc}
\hline PV station & & Original & & Modified \\
& $K_{1}$ & $K_{2}$ & $K_{1}$ & $K_{2}$ \\
\hline Centralized PV inverter & 0.4 & 1.32 & 1.56 \\
Series-connected PV inverter & 1.31 & 0 & 1.01 & 0 \\
\hline
\end{tabular}

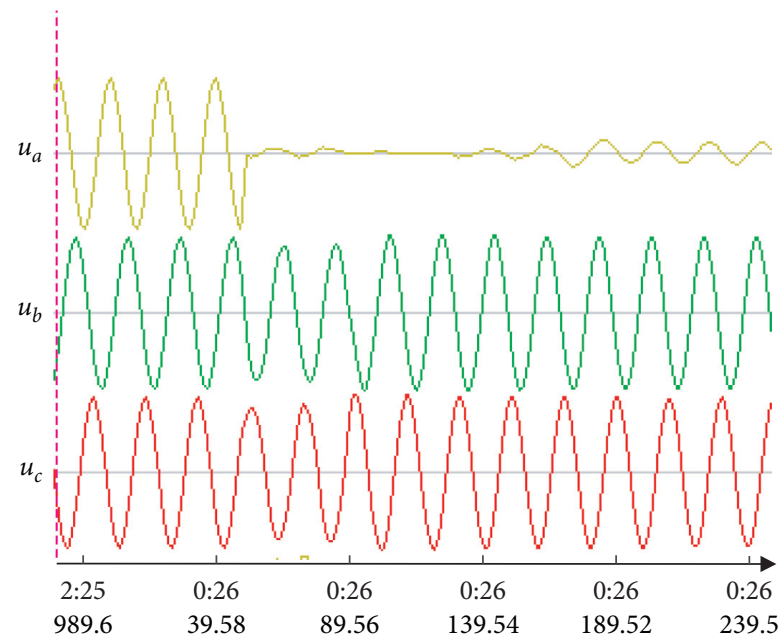

Figure 7: Voltage waveform of transmission line 3-19.

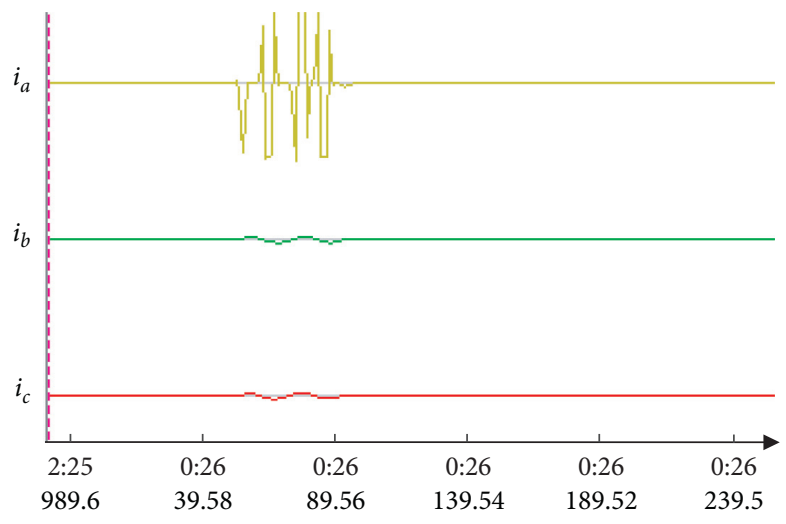

FIgURE 8: Current waveform of transmission line 3-19.

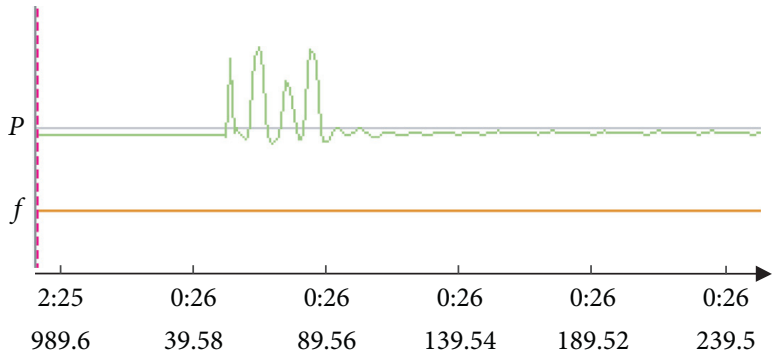

Figure 9: Power and frequency waveform on line 3-19. 


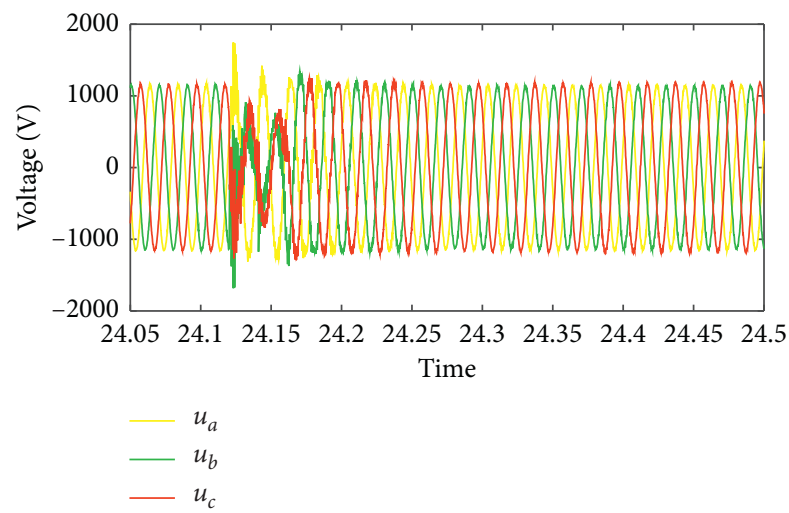

FIgURE 10: Output voltage waveforms of the centralized PV inverter.

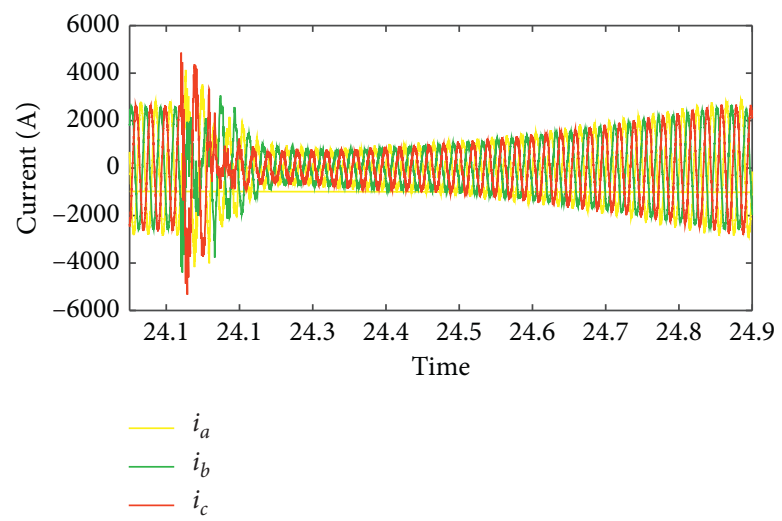

FIGURE 11: Output current waveforms of the centralized PV inverter.

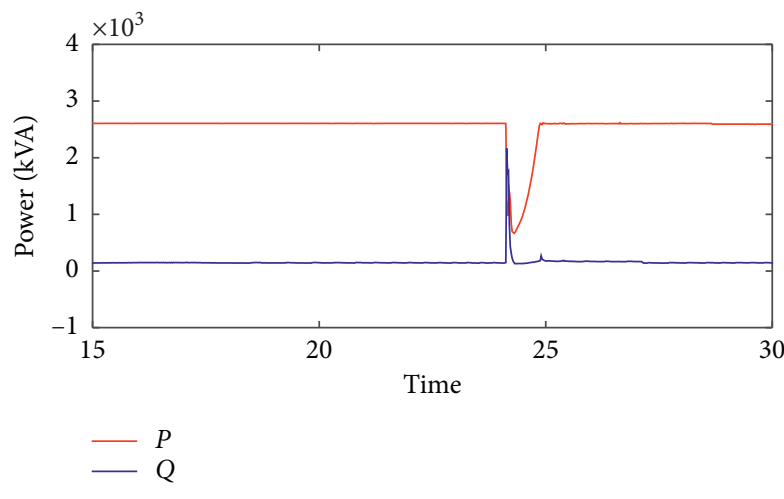

FIGURE 12: Output power of the centralized PV inverter.

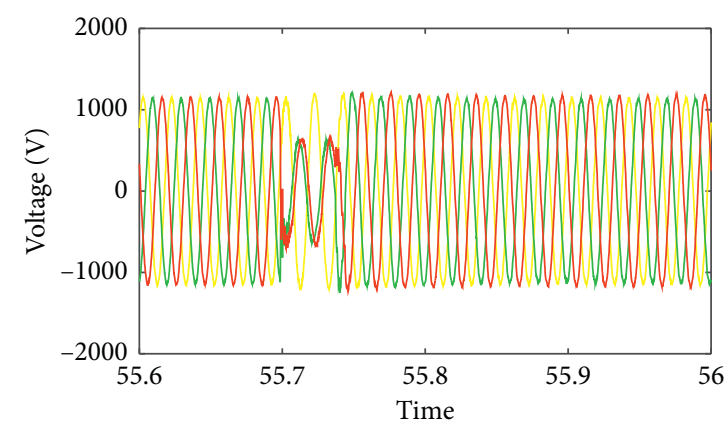

$u_{b}$

$-u_{c}$

FIGURE 13: Output voltage waveforms of the series-connected PV inverter. 


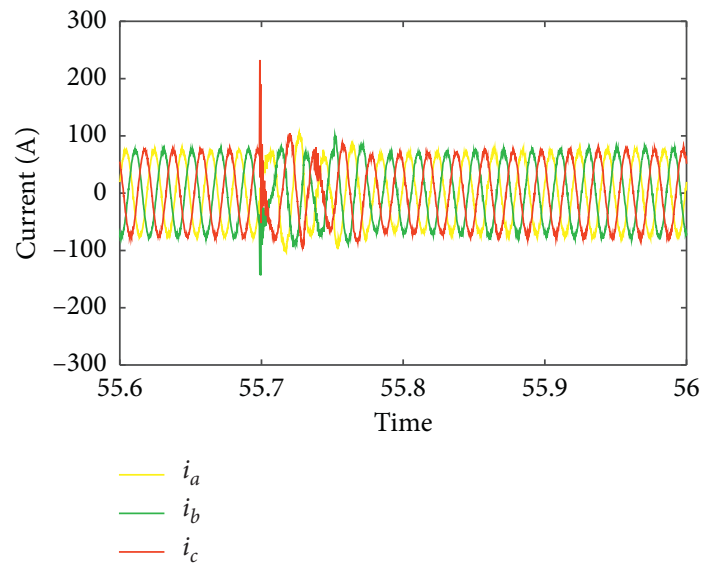

FIgURE 14: Output current waveforms of the series-connected PV inverter.

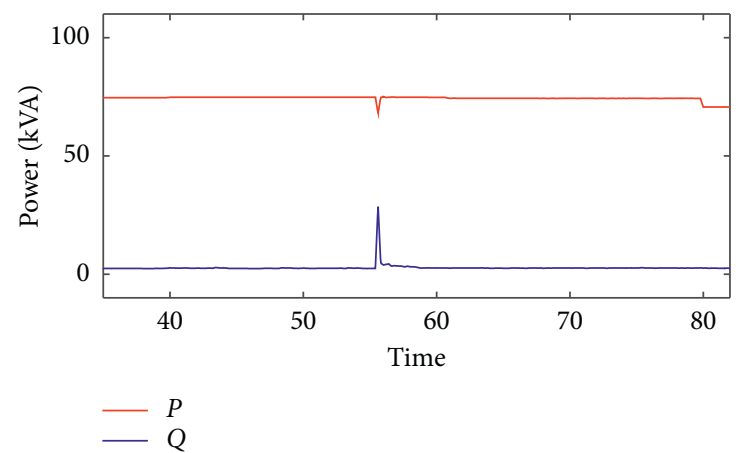

FIGURE 15: Output power of the series-connected PV inverter.

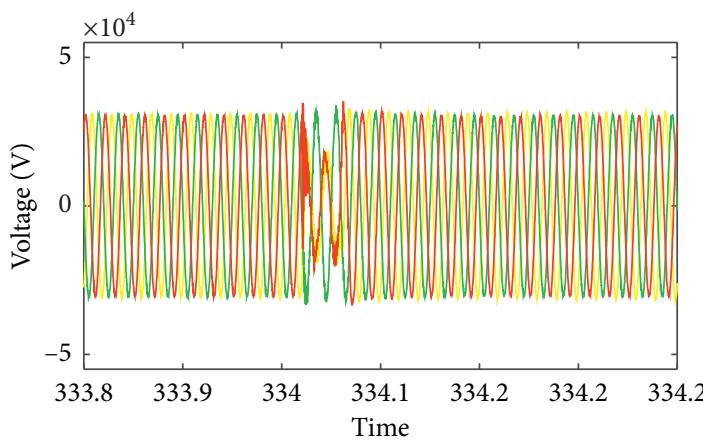

$u_{a}$

$-u_{b}$

$-u_{c}$

FIgURE 16: Voltage waveforms at PCC $_{1}$. 


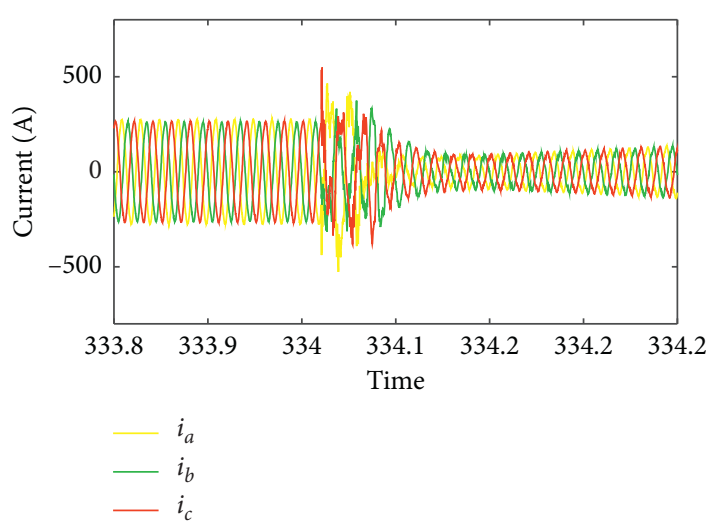

Figure 17: Current waveforms at PCC $_{1}$.

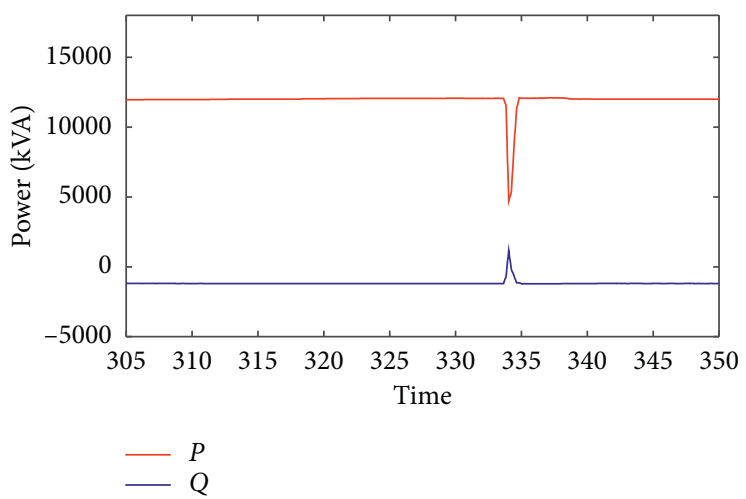

Figure 18: Power flow at $\mathrm{PCC}_{1}$.

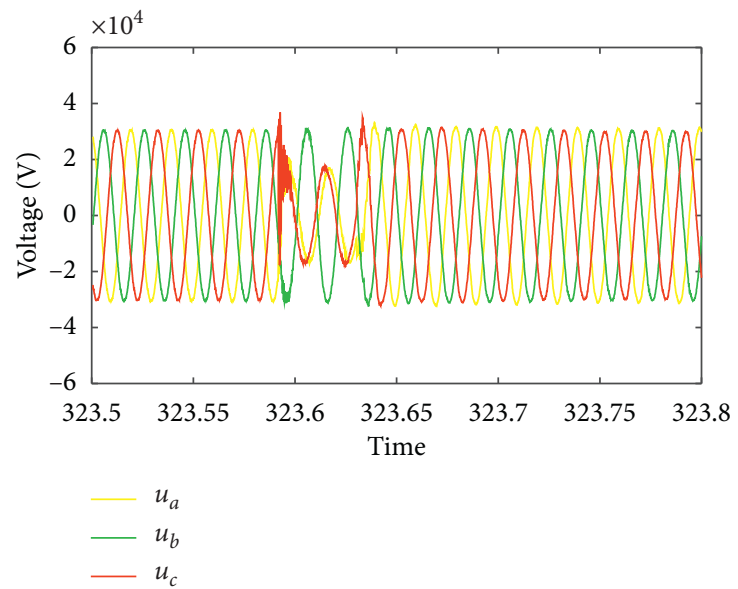

Figure 19: Voltage waveforms at $\mathrm{PCC}_{2}$. 


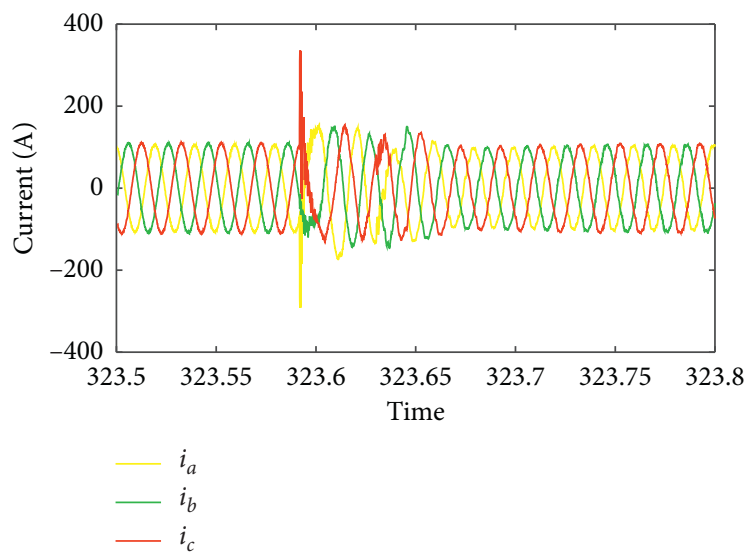

Figure 20: Current waveforms at $\mathrm{PCC}_{2}$.

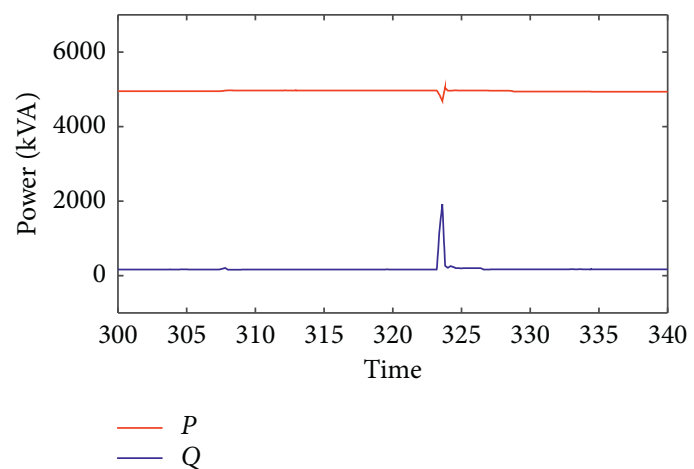

Figure 21: Power flow at $\mathrm{PCC}_{2}$.

TABLe 5: Voltage value at $750 \mathrm{kV}$ substations.

\begin{tabular}{lccc}
\hline Station & $u_{\text {before }}(\mathrm{kV})$ & $u_{\text {after }}(\mathrm{kV})$ & Voltage drop $(\%)$ \\
\hline Station 2 & 446.505 & 344.051 & 22.95 \\
Station 3 & 447.42 & 277.349 & 38.01 \\
Station 4 & 439.684 & 291.556 & 33.69 \\
Station 6 & 438.422 & 354.295 & 19.19 \\
Station 8 & 201.137 & 137.614 & 31.58 \\
Station 11 & 195.322 & 133.143 & 31.23 \\
Station 19 & 199.053 & 37.915 & 86.61 \\
Station 22 & 200.141 & 39.249 & 86.17 \\
\hline
\end{tabular}

TABLE 6: Transmission line voltage value.

\begin{tabular}{lcccc}
\hline Station & Line & $u_{\text {before }}(\mathrm{kV})$ & $u_{\text {after }}(\mathrm{kV})$ & Voltage drop $(\%)$ \\
\hline & $2-6$ & 446.963 & 344.375 & 22.95 \\
& $2-1$ & 446.532 & 344.078 & 22.94 \\
Station 2 & $2-4$ & 446.855 & 344.092 & 23.00 \\
& $2-35$ & 203.175 & 167.189 & 17.71 \\
& $2-36$ & 202.523 & 166.642 & 17.72 \\
& $2-37$ & 203.029 & 167.096 & 17.70 \\
Station 3 & $2-38$ & 203.018 & 167.079 & 38.00 \\
& $3-6$ & 445.532 & 276.217 & 38.01 \\
& $3-4$ & 445.727 & 11.951 & 91.35 \\
\end{tabular}


TABLE 6: Continued.

\begin{tabular}{|c|c|c|c|c|}
\hline Station & Line & $u_{\text {before }}(\mathrm{kV})$ & $u_{\mathrm{after}}(\mathrm{kV})$ & Voltage drop (\%) \\
\hline \multirow{9}{*}{ Station 4} & $4-1$ & 437.51 & 289.99 & 33.72 \\
\hline & $4-2$ & 438.806 & 290.989 & 33.69 \\
\hline & $4-3$ & 437.28 & 290.908 & 33.47 \\
\hline & $4-5$ & 439.117 & 291.03 & 33.72 \\
\hline & $4-8$ & 200.377 & 137.554 & 31.35 \\
\hline & $4-11$ & 201.233 & 138.107 & 31.37 \\
\hline & $4-26$ & 200.716 & 137.75 & 31.37 \\
\hline & 4-15 & 200.663 & 137.738 & 31.36 \\
\hline & 4-18 & 200.734 & 137.75 & 31.38 \\
\hline \multirow{4}{*}{ Station 6} & $6-3$ & 437.09 & 353.268 & 19.18 \\
\hline & $6-4$ & 437.34 & 353.407 & 19.19 \\
\hline & $6-45$ & 436.66 & 352.894 & 19.18 \\
\hline & $6-46$ & 436.993 & 353.185 & 19.18 \\
\hline Station 8 & $8-4$ & 201.166 & 138.347 & 31.23 \\
\hline Station 11 & 4-11 & 193.102 & 132.145 & 31.33 \\
\hline Station 20 & $3-20$ & 200.203 & 30.123 & 84.95 \\
\hline Station 19 & 3-19 & 199.938 & 37.820 & 86.63 \\
\hline Station 22 & $3-22$ & 200.986 & 36.296 & 87.22 \\
\hline
\end{tabular}

voltage value on transmission lines is given in Table $6 . u_{\text {before }}$ is the voltage before the fault, and $u_{\text {after }}$ is the voltage when the fault occurs.

\section{Conclusions}

The dynamic performance of PV inverters in PV station 8 during artificial grounding faults verifies the proposed active support control strategy, which means RES has the capability of disturbance rejection under extreme fault conditions, so it is practical for the RES to regulate voltage and frequency. There are several results seen only during on-site engineering tests:

(1) Through the on-site tests, it is clear that numbers of $\mathrm{PV}$ inverters are disconnected when a short circuit fault occurs. However, it did not occur in the fault simulation device experiments.

(2) Blocking and disconnection of the SVC and SVG are found in both PV stations and substations. Therefore, parameter modification or equipment upgrading is the reasonable solution for them.

(3) The test results reflect potential risks in the power grid operation and reveal predisposing factors of power system instability which is not shown in simulation experiments.

(4) Electromechanical simulation and electromagnetic simulation are practical methods in the power system and RES study, but they cannot fully reflect the electromagnetic characteristics during extreme conditions such as grounding faults and transient voltage sag.

(5) The outstanding benefits of on-site engineering tests are proved.

\section{Data Availability}

The data used to support the findings of this study are included within the article.

\section{Conflicts of Interest}

The authors declare that there are no conflicts of interest regarding the publication of this paper.

\section{Acknowledgments}

This work was supported by the Qinghai Science and Technology Program (Grant no. 2018-GX-A6) and State Grid Jibei Electric Power Company Zhangjiakou Chongli District Power Supply Branch Technology Project.

\section{References}

[1] W. Liu, G. Geng, Q. Jiang, H. Fan, and J. Yu, "Model-free fast frequency control support with energy storage system," IEEE Transactions on Power Systems, vol. 35, no. 4, pp. 3078-3086, 2020.

[2] Y. Wang, Y. Xu, Y. Tang et al., "Aggregated energy storage for power system frequency control: a finite-time consensus approach," IEEE Transactions on Smart Grid, vol. 10, no. 4, pp. 3675-3686, 2019.

[3] F. Cheng, L. Qu, W. Qiao, C. Wei, and L. Hao, "Fault diagnosis of wind turbine gearboxes based on DFIG stator current envelope analysis," IEEE Transactions on Sustainable Energy, vol. 10, no. 3, pp. 1044-1053, 2019.

[4] V. Knap, S. K. Chaudhary, D.-I. Stroe, M. Swierczynski, B.-I. Craciun, and R. Teodorescu, "Sizing of an energy storage system for grid inertial response and primary frequency reserve," IEEE Transactions on Power Systems, vol. 31, no. 5, pp. 3447-3456, 2016.

[5] H. Luo, Z. Hu, H. Zhang, and H. Chen, "Coordinated active power control strategy for deloaded wind turbines to improve regulation performance in AGC," IEEE Transactions on Power Systems, vol. 34, no. 1, pp. 98-108, 2019.

[6] D. Ganger, J. Zhang, and V. Vittal, "Forecast-based anticipatory frequency control in power systems," IEEE Transactions on Power Systems, vol. 33, no. 1, pp. 1004-1012, 2018.

[7] Z. Li, W. Wu, B. Zhang, and B. Wang, "Adjustable robust realtime power dispatch with large-scale wind power integration," 
IEEE Transactions on Sustainable Energy, vol. 6, no. 2, pp. 357-368, 2015.

[8] C. Wei, Z. Shen, D. Xiao, L. Wang, X. Bai, and H. Chen, "An optimal scheduling strategy for peer-to-peer trading in interconnected microgrids based on RO and Nash bargaining," Applied Energy, vol. 295, Article ID 117024, 2021.

[9] R. Patel, C. Li, L. Meegahapola, B. McGrath, and X. Yu, "Enhancing optimal automatic generation control in a multiarea power system with diverse energy resources," IEEE Transactions on Power Systems, vol. 34, no. 5, pp. 3465-3475, 2019.

[10] D. Zhang, H. Zhang, X. Zhang et al., "Research on AGC performance during wind power ramping based on deep reinforcement learning," IEEE Access, vol. 8, pp. 107409$107418,2020$.

[11] R. Prasad and N. P. Padhy, "Synergistic frequency regulation control mechanism for DFIG wind turbines with optimal pitch dynamics," IEEE Transactions on Power Systems, vol. 35, no. 4, pp. 3181-3191, 2020.

[12] X. Chen, J. Lin, F. Liu, and Y. Song, "Optimal control of AGC systems considering non-Gaussian wind power uncertainty," IEEE Transactions on Power Systems, vol. 34, no. 4, pp. 2730-2743, 2019.

[13] K. Doenges, I. Egido, L. Sigrist, E. Lobato Miguélez, and L. Rouco, "Improving AGC performance in power systems with regulation response accuracy margins using battery energy storage system (BESS)," IEEE Transactions on Power Systems, vol. 35, no. 4, pp. 2816-2825, 2020.

[14] F. Zhang, Z. Hu, K. Meng, L. Ding, and Z. Dong, "HESS sizing methodology for an existing thermal generator for the promotion of AGC response ability," IEEE Transactions on Sustainable Energy, vol. 11, no. 2, pp. 608-617, 2020.

[15] Y. Wang, C. Wan, Z. Zhou, K. Zhang, and A. Botterud, "Improving deployment availability of energy storage with data-driven AGC signal models," IEEE Transactions on Power Systems, vol. 33, no. 4, pp. 4207-4217, 2018.

[16] C. Wei, M. Benosman, and T. Kim, "Online parameter identification for state of power prediction of lithium-ion batteries in electric vehicles using extremum seeking," International Journal of Control, Automation and Systems, vol. 17, no. 11, pp. 2906-2916, 2019.

[17] X. L. Su, Z. K. Zhao, S. Yang, and Y. Q. Guo, "Adaptive robust SMC-based AGC auxiliary service control for ESS-integrated PV/wind station," Complexity, vol. 2020, no. 2, 10 pages, Article ID 8879045, 2020.

[18] L. Wang, Q.-S. Vo, and A. V. Prokhorov, "Stability improvement of a multimachine power system connected with a large-scale hybrid wind-photovoltaic farm using a supercapacitor," IEEE Transactions on Industry Applications, vol. 54, no. 1, pp. 50-60, 2018.

[19] H. Karbouj, Z. H. Rather, and B. C. Pal, "Adaptive voltage control for large scale solar PV power plant considering real life factors," IEEE Transactions on Sustainable Energy, vol. 12, no. 2, pp. 990-998, 2021.

[20] R. K. Varma and S. Mohan, "Mitigation of fault induced delayed voltage recovery (FIDVR) by PV-STATCOM," IEEE Transactions on Power Systems, vol. 35, no. 6, pp. 4251-4262, 2020.

[21] X. Tian, Y. Chi, Y. Li, H. Tang, C. Liu, and Y. Su, "Subsynchronous oscillation coordinated damping optimization control of DFIG and SVG and self-optimization parameter tuning method," CSEE Journal of Power and Energy Systems, vol. 7, no. 1, pp. 140-149, 2021.
[22] S. Wang, Y. Dong, L. Wu, and B. Yan, "Interval overvoltage risk based PV hosting capacity evaluation considering PV and load uncertainties," IEEE Transactions on Smart Grid, vol. 11, no. 3, pp. 2709-2721, 2020.

[23] C. Mao, F. Leng, J. Li et al., "A 400-V/50-kVA digital-physical hybrid real-time simulation platform for power systems," IEEE Transactions on Industrial Electronics, vol. 65, no. 5, pp. 3666-3676, 2018.

[24] L. Wang, Y. Shi, Y. Shi, R. Xie, and H. Li, "Ground leakage current analysis and suppression in a 60-kW 5-level T-type transformerless SiC PV inverter," IEEE Transactions on Power Electronics, vol. 33, no. 2, pp. 1271-1283, 2018.

[25] R. D. Zimmerman, C. E. Murillo-Sánchez, and R. J. Thomas, "MATPOWER: steady-state operations, planning, and analysis tools for power systems research and education," IEEE Transactions on Power Systems, vol. 26, no. 1, pp. 12-19, 2011.

[26] S. S. M. Reshikeshan, S. L. Matthiesen, M. S. Illindala, A. A. Renjit, and R. Roychowdhury, "Autonomous voltage regulation by distributed PV inverters with minimal internode interference," IEEE Transactions on Industry Applications, vol. 57, no. 3, pp. 2058-2066, 2021.

[27] S. Rahman, S. Saha, S. N. Islam et al., "Analysis of power grid voltage stability with high penetration of solar PV systems," IEEE Transactions on Industry Applications, vol. 57, no. 3, pp. 2245-2257, 2021.

[28] S. B. Q. Naqvi, S. Kumar, and B. Singh, "Weak grid integration of a single-stage solar energy conversion system with power quality improvement features under varied operating conditions," IEEE Transactions on Industry Applications, vol. 57, no. 2, pp. 1303-1313, 2021.

[29] J. Ma, S. Wang, Y. Qiu, Y. Li, Z. Wang, and J. S. Thorp, “Angle stability analysis of power system with multiple operating conditions considering cascading failure," IEEE Transactions on Power Systems, vol. 32, no. 2, pp. 873-882, 2016.

[30] P. N. Korovesis, G. A. Vokas, I. F. Gonos, and F. V. Topalis, "Influence of large-scale installation of energy saving lamps on the line voltage distortion of a weak network supplied by photovoltaic station," IEEE Transactions on Power Delivery, vol. 19, no. 4, pp. 1787-1793, 2004. 